\title{
Kompetensi Operasional Pengalaman Lapangan Industri
}

\author{
Abillio De Octantio ${ }^{1}$, Lise Asnur ${ }^{2}$ \\ 1,2 Universitas Negeri Padang, Padang, Indonesia
}

\begin{abstract}
Keywords:

Operational

Competence;

Industrial Field

Experience

Abstract: The COVID-19 pandemic has an impact on students who cannot complete the PLI period. Of course, this is very influential on the operational competence of students. This study aims to analyze the Operational Competence of industrial field experience related to problems during the implementation of Industrial Field Experience related to operational competencies, namely motives, traits, self-concept, knowledge, and skills when students carry out PLI. This study uses a quantitative descriptive method with a total sample of 74 people from a total of 280 people. This research consists of one variable, namely operational competence. This study uses data analysis techniques in the form of percentages with categorization divided into very good category, good category, sufficient category, bad category and very bad category. This data was analyzed using the SPSS version 20.00 program and the results of the research that had been carried out were obtained in the form of industrial field experience which was included in the sufficient category (82.43\%). So, this shows the lack of knowledge, abilities and skills of students in the operational field due to the covid-19 pandemic. The implication of this research is expected to increase the operational competence of students.

Abstrak: Pandemic covid-19 memberikan dampak pada mahasiswa yang tidak dapat menyelesaikan masa PLI. Tentu hal ini sangat berpengaruh terhadap kompetensi operasional mahasiswa. Penelitian ini bertujuan untuk menganalisis kompetensi operasional pengalaman lapangan industri berkaitan dengan masalah pada saat pelaksanaan Pengalaman Lapangan Industri yang berkaitan dengan kompetensi operasional yaitu, motive, traits, self-concept, knowledge, and skills pada saat mahasiswa melaksanakan PLI. Penelitian ini menggunakan metode deskriptif kuantitatif dengan total sampel sebanyak 74 orang dari total 280 orang. Penelitian ini terdiri dari satu variabel yaitu kompetensi operasional. Penelitian ini menggunakan teknik analisis data berupa persentase dengan jenjang kategori sangat baik, baik, cukup, buruk, dan sangat buruk. Data ini dianalisis menggunakan program SPSS versi 20.00. Dari penelitian yang telah dilakukan diperoleh hasilnya berupa pengalaman lapangan industri termasuk dalam kategori cukup (82,43\%). Hasil ini menunjukkan bahwa kurangnya pengetahuan, kemampuan, serta keterampilan mahasiswa di bidang operasional karena pandemic covid-19. Implikasi penelitian ini diharapkan dapat meningkatkan kompetensi operasional mahasiswa.
\end{abstract}

Alamat Korespondensi:

E-mail: abiliooctantio@gmail.com (Octantio)

\section{Pendahuluan}

Berkembangnya industri perhotelan menarik banyak tenaga kerja di sektor pariwisata dan perhotelan. Secara tidak langsung, perkembangan ini meningkatkan permintaan industri perhotelan terkait dengan kesediaan tenaga kerja yang terdidik dan juga berkualitas (Arifin et al., 2012; Nurizzaman, 2020). Sumber Daya Manusia (SDM) berperan untuk pengembangan dan peningkatan pembangunan di bidang ekonomi dan sosial (Suryani, 2019; Wahyono et al., 2020). Kemajuan suatu organisasi sangat dipengaruhi oleh prestasi sumber daya manusia, Oleh karena itu, manajemen sumber daya manusia baik instansi swasta maupun pemerintahan perlu mengupayakan teknik dan

$\begin{array}{ll}\text { History: } & \\ \text { Received } & : 20 \text { Mei } 2021 \\ \text { Revised } & : 23 \text { Mei } 2021 \\ \text { Accepted } & : 6 \text { Juli } 2021 \\ \text { Published } & : 25 \text { Juli } 2021\end{array}$

Publisher: Undiksha Press

Licensed: This work is licensed under a Creative Commons Attribution 3.0 License

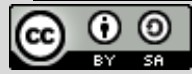


strategi peningkatan prestasi karyawan. Bangsa Indonesia saat ini dihadapkan pada suatu tantangan yang semakin besar. Arus informasi dan kemajuan ilmu pengetahuan dan teknologi cepat dan mengubah segala bentuk sendi kehidupan. Kenyataan itu telah memacu bangsa Indonesia untuk berbuat lebih baik dengan cara meningkatkan kualitas sumber daya manusia tersebut. Secara nyata, sumber daya manusia adalah sebagai penyelengga dalam pelaksana pembangunan di segala bidang. Pengembangan sumber daya manusia dapat dilakukan dengan berbagai cara, salah satunya praktik ilapangan. Praktek lapangan industri dirancang agar mahasiswa tidak hanya mempelajari secara teori tentang pembelajaran tetapi juga sebagai bentuk implementasi dan aplikasi pelajaran selama di kampus untuk dapat diterapkan di perusahaan/industri tempat magang.

Namun kenyataan saat ini, pandemic covid-19 pada akhirnya sangat berimbas pada mahasiswa yang harus segera dipulangkan dan tidak dapat menyelesaikan masa PLI. Tentu hal ini sangat berpengaruh terhadap kompetensi operasional mahasiswa. Masalah sumber daya manusia salah satu penyebab proses pembangunan yang berjalan selama ini kurang didukung oleh produktivitas tenaga kerja yang memadai. Permasalahan ini memengaruhi kompetensi yang dimiliki mahasiswa. Kompetensi operasional merupakan sebuah kemampuan/kompetensi pada aspek penyusunan bentuk usaha dan sistem yang dipakai dalam menjalankan usaha (Yamit, 2010). Kompetensi operasional juga dinilai dari seberapa baik hasil dari suatu pekerjaan yang dilakukan hingga pekerjaan tersebut berakhir. Kompetensi sebagai karakteristik yang mendasari seseorang berkaitan dengan efektivitas kinerja individu dalam pekerjaanya atau karakteristik dasar individu yang memiliki hubungan kausal atau sebab akibat dengan kriteria yang dijadikan acuan, efektif atau berkinerja prima atau superior di tempat kerja atau pada situasi tertentu. Terdapat 5 (lima) karakteristik kompetensi, yaitu (1) Motive, (2) Traits, (3) Self-concept, (4) Knowledge, dan (5) Skills (Fariza et al., 2019).

Praktik kerja lapangan juga bisa disebut sebagai Program Pengalaman Industri (PPI) adalah program latihan yang diselenggarakan di lapangan atau di luar kelas dalam rangkaian pembelajaran sebagai bagian integral program pelatihan. Pengalaman Lapangan Industri (PLI) adalah suatu program latihan yang diselenggarakan mahasiswa di luar kampus untuk mengaplikasikan pembelajaran yang telah diperolehnya di kelas dan diterapkan di industri (Maryono et al., 2018; Ramayanti, 2021). Selain itu, mahasiswa juga dapat bertukar wawasan dan keterampilan yang tidak didapat selama di kampus. Harapannya mahasiswa Indonesia bisa membuat suatu program agar menjadi sukses bila selesai kuliah. Pengalaman mempunyai pengaruh yang positif atau baik terhadap kesiapan. Mahasiswa dapat langsung merasakan kondisi kerja dan pengalaman-pengalaman baru yang ada di lapangan, sehingga memberikan tambahan pengetahuan baik itu pengetahuan tentang keteknikan maupun pengetahuan tentang manajemen perusahaan.

Temuan penelitian yang sejalan menyatakan PLI akan dapat meningkatkan kemampuan maupun minat mahasiswa dalam berwirausaha (Gusmardiansah \& Rifdarmon, 2021). PLI secara langsung akan membuat mahasiswa mengetahui aspek-aspek tertentu, sehingga akan muncul keinginan untuk meniru kesuksesan perusahaan/industri yang ditempati (Ramayanti, 2021). Penelitian ini bertujuan untuk menganalisis kompetensi operasional yang dimiliki oleh mahasiswa Manajemen Perhotelan UNP tahun masuk 2018 melalui PLI 1 yang lebih banyak mengambil pada bagian operasional seperti Front Office, Food Beverage Service and Product serta Housekeeping. Mereka melaksanakan Pengalaman Lapangan Industri di masa pandemic covid 19. Kemampuan yang mereka dapatkan selama hanya 2-3 bulan masa pelaksanaan PLI lebih dari cukup atau kurang dapat dilihat dari indikator kompetensi operasional dalam kaitannya dengan pelaksanaan PLI.

\section{Metode}

Penelitian ini menggunakan metode penelitian deskriptif dengan data kuantitatif. Penelitian ini menggunakan metode survey. Data dianalisis dan diolah sesuai dengan tujuan dan pertanyaan penelitian. Penelitian ini menggunakan variable mandiri yaitu kompetensi operasional. Populasi penelitian ini adalah mahasiswa D4 Manajemen Perhotelan UNP tahun masuk 2018 yang sudah melaksanakan Praktik Lapangan Industri menggunakan jenis purposive sampling. Data dalam 
penelitian ini menggunakan data primer dan data sekunder. Teknik pengumpulan data dilakukan dengan cara menyebar angket/kuesioner yang tersusun. Sampel penelitian menggunakan uji coba sebanyak 30 responden. Lalu dilakukan uji coba instrumen penelitian menggunakan uji validitas dan uji reliabilitas. Teknik analisis yang digunakan analisis deskriptif kuantitatif.

\section{Hasil dan Pembahasan}

\section{Hasil Penelitian}

Pengujian berdasarkan pada indicator motive. Motive merupakan hal yang dilakukan seseorang yang didorong oleh keinginan sendiri untuk mencapai tujuan tertentu. Hal ini diperoleh melalui angket yang disebarkan kepada 74 responden. Hasilnya, validitas dan reliabilitasnya telah memenuhi syarat. Jumlah pernyataan yang diberikan sebanyak 30 butir yang diisi oleh sejumlah responden. Berikut hasil olahan data dari responden.

Tabel 1. Skor Jawaban Responden tentang Motive

\begin{tabular}{|c|c|c|c|}
\hline Kategori & Rentang skor & $\mathbf{F}$ & $\%$ \\
\hline Sangat baik & $\geq 19,995$ & 60 & 81,08 \\
\hline Baik & $16,665-<19,995$ & 14 & 18,91 \\
\hline Cukup & $13,335-<16,665$ & 0 & 0 \\
\hline Buruk & $10,005-<13,335$ & 0 & 0 \\
\hline Sangat buruk & $<10,005$ & 0 & 0 \\
\hline \multicolumn{2}{|c|}{ Jumlah } & 74 & 100 \\
\hline
\end{tabular}

Keterangan: Hasil Olahan Microsoft Excel, 2021

Pada tabel 1 dapat dilihat capaian pada kategori motive Pengalaman Lapangan Industri Prodi D4 Manajemen Perhotelan UNP tahun masuk 2018 digolongkan dalam kategori sangat baik, yaitu sebesar $81,08 \%$ mahasiswa dari keseluruhan 74 mahasiswa yang mengisi angket. Dapat disimpulkan bahwa indikator motive Pengalaman Lapangan Industri bagi mahasiswa D4 Manajemen Perhotelan UNP tahun masuk 2018 sangat baik dengan presentase 81,08\%. Traits ialah karakter dari seseorang yang membuat seseorang berperilaku. Mahasiswa akan dinilai dari sifat yang mereka terapkan selama melaksanakan PLI. Pada praktiknya, lama pelaksanaan PLI dilaksanakan berdasarkan capaian target kompetensi disesuaikan dengan standar keahlian. Pengalaman Lapangan Industri dilaksanakan oleh Program Studi D4 Manajemen Perhotelan di Jurusan Pariwisata Universitas Negeri Padang selama 180 hari atau 6 bulan.

Tabel 2. Skor Jawaban Responden Tentang Traits

\begin{tabular}{|c|c|c|c|}
\hline Kategori & Rentang skor & $\mathbf{F}$ & $\%$ \\
\hline Sangat baik & $\geq 19,995$ & 51 & 68,91 \\
\hline Baik & $16,665-<19,995$ & 23 & 31,09 \\
\hline Cukup & $13,335-<16,665$ & 0 & 0 \\
\hline Buruk & $10,005-<13,335$ & 0 & 0 \\
\hline Sangat buruk & $<10,005$ & 0 & 0 \\
\hline \multicolumn{2}{|c|}{ Jumlah } & 74 & 100 \\
\hline
\end{tabular}

Keterangan: Hasil Olahan Microsoft Excel, 2021

Tabel 2 menunjukan hasil jawaban dari indikator traits pada Pengalaman Lapangan Industri Prodi D4 Manajemen Perhotelan UNP tahun masuk 2018 digolongkan dalam kategori sangat baik sebesar 68,91\% dari total keseluruhan 74 mahasiswa. 


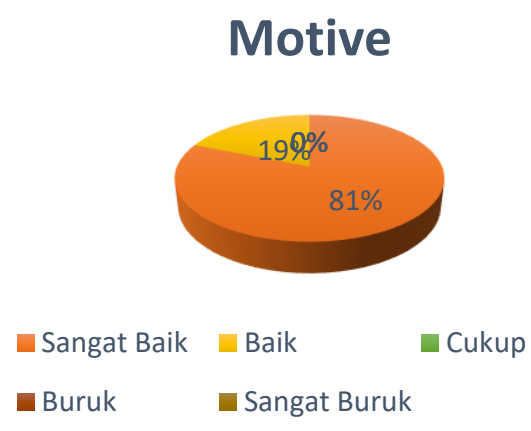

Gambar 1. Persentase Motive Pengalaman Lapangan Industri

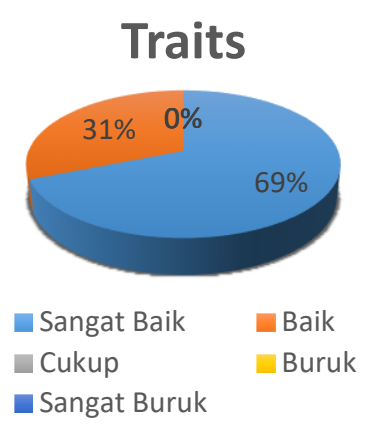

Gambar 2. Persentase Traits Pengalaman Lapangan Industri

Visualisasi dari gambar 2 tentang indicator traits Pengalaman Lapangan Industri Prodi D4 Manajemen Perhotelan UNP tahun masuk 2018 dalam kategori sangat baik dengan presentase $68,91 \%$. Self-concept adalah upaya seseorang memandang dan menghargai dirinya sendiri serta lingkungan tempat dia bekerja, sehingga akhirnya menjadi pendukung pada saat dia diberikan tanggung jawab oleh perusahaan. Berikut ini tabel data penelitian di program studi D4 Manajemen Perhotelan UNP tahun masuk 2018:

Tabel 3. Skor Jawaban Responden tentang Self-concept

\begin{tabular}{|c|c|c|c|}
\hline Kategori & Rentang skor & $\mathbf{F}$ & $\%$ \\
\hline Sangat baik & $\geq 15,99$ & 43 & 58,10 \\
\hline Baik & $13,33-<15,99$ & 21 & 28,37 \\
\hline Cukup & $10,67-<13,33$ & 10 & 13,51 \\
\hline Buruk & $8,01-<10,67$ & 0 & 0 \\
\hline Sangat buruk & $<10,005$ & 0 & 0 \\
\hline
\end{tabular}

Keterangan: Hasil Olahan Microsoft Excel, 2021

Tabel 3 menjelaskan capaian tingkat kategori self-concept Pengalaman Lapangan Industri di Jurusan Pariwisata UNP program studi D4 Manajemen Perhotelan tahun masuk 2018 termasuk dalam kategori sangat baik yaitu sebesar $58,10 \%$ dari total 74 mahasiswa. Penjelasan gambar 3 menggambarkan hasil capaian tentang self-concept Pengalaman Lapangan Industri di D4 Manajemen Perhotelan UNP tahun masuk 2018 dalam kategori sangat baik dengan presentase 47,29\%. Knowledge adalah pengetahuan yang dimiliki seseorang dalam ruang lingkup kerja tertentu, yang didapatkan dari hasil belajar dan menggali informasi terkait bidang yang diminati. Berikut table skor jawaban.

Tabel 4. Skor Jawaban Responden tentang Knowledge

\begin{tabular}{|c|c|c|c|}
\hline Kategori & Rentang skor & $\mathbf{F}$ & $\%$ \\
\hline Sangat baik & $\geq 39,99$ & 0 & 0 \\
\hline Baik & $33,33-<39,99$ & 1 & 1,35 \\
\hline Cukup & $26,67-<33,33$ & 8 & 10,81 \\
\hline Buruk & $20,01-<26,67$ & 59 & 79,72 \\
\hline Sangat buruk & $<20,01$ & 6 & 8,10 \\
\hline
\end{tabular}

Keterangan: Hasil Olahan Microsoft Excel, 2021 
Tabel 4 menerangkan skor terkait pengetahuan yang didapatkan mahasiswa selama melaksanakan PLI kurang dari waktu yang seharusnya. Diketahui bahwa Pengalaman Lapangan Industri di Prodi D4 Manajemen Perhotelan UNP tahun masuk 2018 termasuk dalam kategori buruk. Persentase yang ditunjukkan di program program studi D4 Manajemen Perhotelan UNP tahun masuk 2018 yaitu sebesar 72,72 \% dari keseluruhan 74 mahasiswa. Data tersebut menunjukkan pada indicator knowledge Pengalaman Lapangan Industri Prodi D4 Manajemen Perhotelan UNP ahun masuk 2018 termasuk dalam kategori Buruk dengan persentase 72,97\%. Hal ini menguatkan bahwa pelaksanaan PLI pada periode yang kurang dari normalnya dapat mengurangi pengetahuan mahasiswa. Ilmu yang didapatkan masih sangat kurang, terutama pada bidang operasional karena pada bidang ini dituntut pengalaman kerja. Optimalisasi pada indicator ini mahasiswa dapat menambah pengetahuan dengan melakukan pekerjaan DW (Daily Worker) pada bidang yang mereka minati. Berikut persentase capaian indicator knowledge.

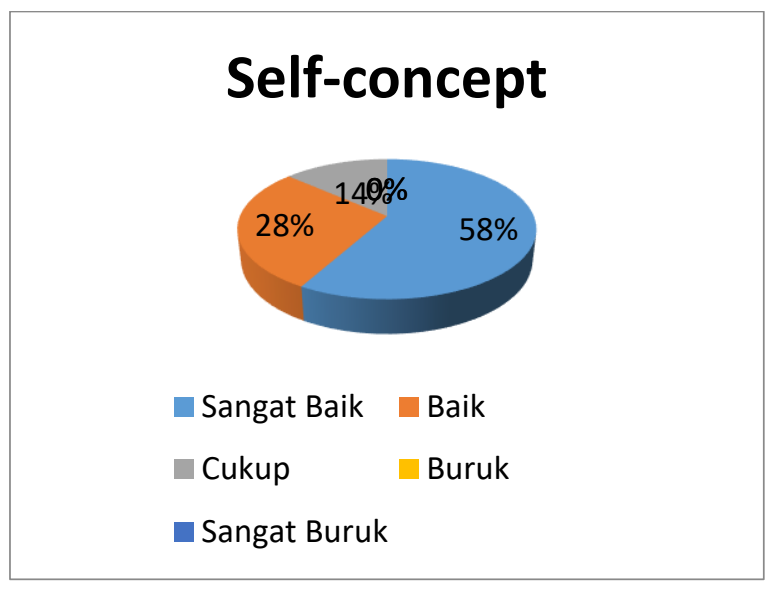

Gambar 3. Persentase Self-concept Pengalaman Lapangan Industri

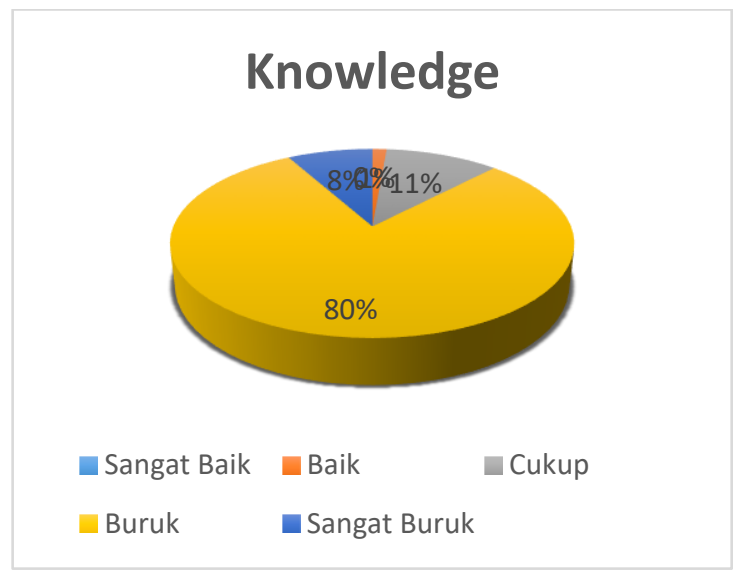

Gambar 4. Persentase Knowledge Pengalaman Lapangan Industri

Skills adalah kemampuan yang dimiliki seseorang berkat hasil kinerja yang ditekuni didasarkan pada keinginan dan ketertarikan pada bidang tertentu. Berikut Hasil capaian pada skor jawaban skills.

Tabel 5. Skor Jawaban Responden Tentang Skills

\begin{tabular}{|c|c|c|c|}
\hline Kategori & Rentang skor & $\mathbf{F}$ & $\%$ \\
\hline Sangat baik & $\geq 24$ & 0 & 0 \\
\hline Baik & $20-<23$ & 1 & 1,35 \\
\hline Cukup & $16-<19$ & 6,75 & 6,75 \\
\hline Buruk & $12-<15$ & 58 & 78,37 \\
\hline Sangat buruk & $<12$ & 10 & 13,51 \\
\hline \multicolumn{2}{|c|}{ Jumlah } & 74 & 100 \\
\hline
\end{tabular}

Keterangan: Hasil Olahan Microsoft Excel, 2021

Pada table ini dapat dilihat skor jawaban responden terkait indicator skills pada Pengalaman Lapangan Industri Prodi D4 Manajemen Perhotelan UNP tahun masuk 2018 termasuk dalam kategori buruk. Persentase yang ditunjukkan pada Prodi D4 Manajemen Perhotelan UNP tahun masuk 2018 yaitu sebesar $78,37 \%$ dari keseluruhan 74 mahasiswa. Kesimpulannya, skills PLI Prodi D4 Manajemen Perhotelan UNP tahun masuk 2018 termasuk dalam kategori Buruk dengan presentase 78,37\%. Gambaran persentase pada indicator skills Kompetensi operasional Pengalaman Lapangan Industri Prodi D4 Manajemen Perhotelan UNP tahun masuk 2018 dapat dilihat pada table berikut. 
Tabel 6. Skor Jawaban Responden Keseluruhan tentang Kompetensi Operasional

\begin{tabular}{|c|c|c|c|}
\hline Kategori & Rentang skor & $\mathbf{F}$ & $\%$ \\
\hline Sangat baik & $\geq 120$ & 0 & 0 \\
\hline Baik & $100-<129$ & 0 & 0 \\
\hline Cukup & $80-<99$ & 61 & 82,43 \\
\hline Buruk & $60-<79$ & 13 & 18,91 \\
\hline Sangat buruk & $<60$ & 0 & 0 \\
\hline \multicolumn{2}{|c|}{ Jumlah } & 74 & 100 \\
\hline
\end{tabular}

Keterangan: Hasil Olahan Microsoft Excel, 2021

Tabel tersebut menjelaskan hasil keseluruhan dari variable kompetensi operasional pada mahasiswa Pengalaman Lapangan Industri Prodi D4 Manajemen Perhotelan UNP tahun masuk 2018 dengan kategori cukup. Kesimpulan dari variable kompetensi operasional pada mahasiswa PLI Prodi D4 Manajemen Perhotelan UNP tahun masuk 2018 termasuk dalam kategori Cukup dengan presentase $82,43 \%$.

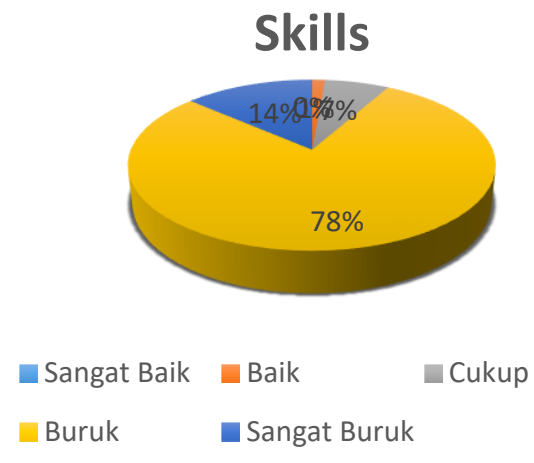

Gambar 5. Presentase Skills Pengalaman Lapangan Industri

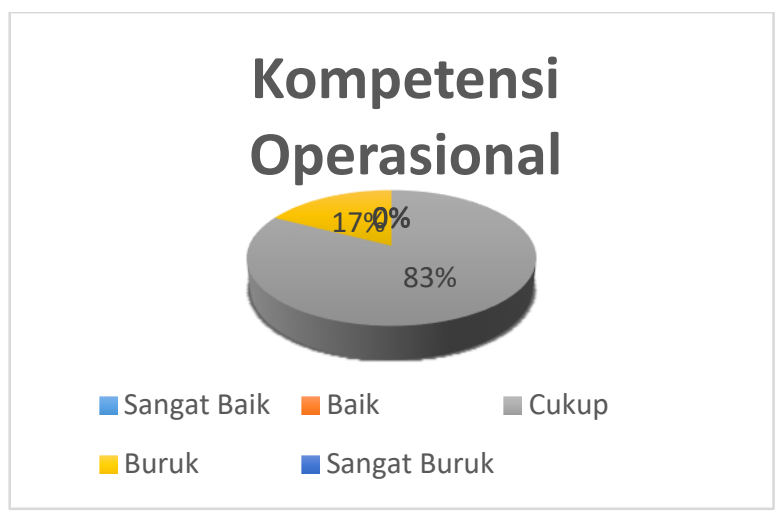

Gambar 6. Presentase Kompetensi Operasional Pengalaman Lapangan Industri

\section{Pembahasan}

Berdasarkan hasil penelitian, karakteristik kompetensii operasional terdiri dari motive, traits, self-concept, mnowledge, dan skills. Motivasi berasal dari kata motif yang dapat diartikan sebagai kekuatan yang terdapat dalam diri individu, yang menyebabkan individu tersebut bertindak atau berbuat. Hasil penelitian pada indicator motive merupakan hal-hal yang mendorong seseorang melakukan pekerjaan yang didasari oleh keinginannya melakukan pekerjaan tersebut dan memotivasi diri sendiri untuk mencapai tujuan tertentu Pengalaman Lapangan Industri menunjukan bahwa sebanyak $81,08 \%$ dari mahasiswa yang menjadi sampel termasuk dalam kategori sangat baik (Tjiptono, 2012). Hasil penelitian pada indicator traits disimpulkan sikap yang dimiliki oleh seseorang yang timbul akibat dorongan dari diri sendiri yang tidak dapat dilihat dalam halnya dalam melaksanakan Pengalaman Lapangan Industri dicapai nilai sebanyak 68,91\%, dikategorikan Sangat Baik.

Hasil penelitian indikator self-concept sikap ataupun nilai yang dimiliki oleh diri seseorang dinilai dari seberapa bernilainya seseorang dan apa yang membuat seseorang tertarik melakukan sesuatu. Pengalaman Lapangan Industri pada indicator tersebut menunjukkan bahwa sebanyak 58,10\% mahasiswa Program Studi D4 Manajemen Perhotelan UNP tahun masuk 2018 yang menjadi sampel masuk dalam kategori sangat baik. Self concept merupakan bagian penting dalam perkembangan kepribadian. Seperti dikemukakan oleh Rogers bahwa konsep kepribadian yang paling utama adalah diri. Diri (self) berisi ide-ide, persepsi-persepsi dan nilai-nilai yang mencakup kesadaran 
tentang diri sendiri. Konsep diri merupakan representasi diri yang mencakup identitas diri yakni karakteristik personal, pengalaman, peran, dan status sosial (Desmita, 2012).

Indikator knowledge dalam penelitian ini adalah pengetahuan yang dimiliki seseorang dalam

bidang tertentu. Pengalaman Lapangan Industri pada indicator tersebut mendapat hasil sebanyak 79,72\% dari mahasiswa Program Studi D4 Manajemen Perhotelan UNP tahun masuk 2018 yang menjadi sampel termasuk dalam kategori buruk. Menurut Sugihartono (2012: 105), pengetahuan dibangun dalam diri seorang individu melalui proses interaksi yang berkesinambungan dengan lingkungan. Skills atau kemampuan dalam bidang operasional hotel bisa didapatkan dari pengalaman selama melaksanakan PLI. Biasanya mahasiswa yang baru pulang PLI mendapatkan kemampuan baru yang mereka dapatkan dari hasil melaksanakan PLI selama 6 bulan. Lain halnya dengan mahasiswa Pengalaman Lapangan Industri Prodi D4 Manajemen Perhotelan UNP tahun masuk 2018. Mereka melaksanakan PLI kurang dari waktu yang dijadwalkan bahkan ada yang belum melaksanakan PLI sama sekali, sehingga kemampuan mahasiswa tersebut dalam bidang operasional dikategorikan buruk karena belum atau kurangnya ilmu yang mereka dapatkan. Skills menjadi salah satu indicator (Tjiptono, 2014) yang menentukan kemampuan yang seorang miliki mecakup kemampuan akademis maupun non-akademis atau keterampilan yang dimiliki oleh seseorang berdasarkan profesi yang ditekuni. Pada indicator ini mendapat hasil persentase 78,37\% dengan kategori buruk.

Berdasarkan pembahasan, kompetensi operasional Pengalaman Lapangan Industri di Program Studi D4 Manajemen Perhotelan UNP tahun masuk 2018 termasuk dalam kategori Cukup. Hal ini dapat diartikan bahwa kemapuan mahasiswa terutama di bidang operasional masih sangat kurang. Hal ini diperburuk dengan adanya pandemi covid-19, sehingga masa pelaksanaan PLI harus dikurangi. Pengurangan tersebut tentu sangat berimbas kepada mahasiswa yang masih dalam tahap pembelajaran dalam hal praktik di bidang operasional yang menuntut pengalaman dalam bekerja. Kompetensi operasional memiliki 5 indikator yaitu motive, traits, self-concept, knowledge, skills. Dari 5 indikator tersebut pada indicator motive, traits, self-concept memperoleh hasil sangat baik. Mahasiswa mampu mengenali diri mereka dengan baik dan mampu mempresentasikannya terhadap pekerjaan yang mereka senangi. Sedangkan pada indicator motive, traits, self-concept memperoleh persentase buruk. Hal tersebut menjelaskan kurangnya pengetahuan, kemampuan, serta keterampilan mahasiswa di bidang operasional karena pandemic covid-19 membuat terhambatnya pelaksanaan PLI Program Studi D4 Manajemen Perhotelan UNP tahun masuk 2018.

\section{Simpulan}

Kompetensi operasional Pengalaman Lapangan Industri di Program Studi D4 Manajemen Perhotelan UNP tahun masuk 2018 termasuk dalam kategori Cukup. Hal ini disebabkan indicator motive, traits, self-concept memperoleh persentase buruk. Hal ini menunjukkan bahwa kurangnya pengetahuan, kemampuan, serta keterampilan mahasiswa di bidang operasional karena pandemi covid-19 membuat terhambatnya pelaksanaan PLI Program Studi D4 Manajemen Perhotelan UNP tahun masuk 2018.

\section{Daftar Pustaka}

Arifin, Z., Indonesia, U. P., \& Kejuruan, S. M. (2012). Implementasi Manajemen Stratejik Berbasis Kemitraan dalam Meningkatkan Mutu SMK (Studi Pada SMK Kelompok Teknologi Bidang Otomotif di Kota Yogyakarta). Jurnal Administrasi Pendidikan UPI, 14(1), 60-70. https://doi.org/10.17509/jap.v14i1.6708.

Fariza, U., Rachma, N., \& Hufron, M. (2019). Pengaruh Service Quality terhadap Customer Loyalty Dimediasi Customer Satisfaction dan Switching Cost sebagai Variabel Moderating. Jurnal Riset Manajemen, 8 No.15, 100-114.

Gusmardiansah, \& Rifdarmon. (2021). The Effect Of The Implementation Of Industrial Field Experience on Enterprise Interest in Automotive Engineering Students Faculty Of Engineering Padang State University Pengaruh Pelaksanaan Pengalaman Lapangan Industri terhadap 
Minat Berwirausaha pada Mah. AEEJ : Journal of Automotive Engineering and Vocational Education, 2(1), 21-32. https://doi.org/10.24036/aeej.v2i1.35.

Maryono, A., Harrison, R. L., Cooke, D. R., Rompo, I., \& Hoschke, T. G. (2018). Tectonics and Geology of Porphyry Cu-Au Deposits along the Eastern Sunda Magmatic Arc, Indonesia. Economic Geology, 113(1), 7-38. https://doi.org/10.5382/econgeo.2018.4542.

Nurizzaman, R. (2020). Analisis Kepatuhan Perpajakan Pelaku Usaha Mikro, Kecil, dan Menengah (Umkm) di Indonesia: Studi pada Kota Banjarbaru Kalimantan Selatan. Jurnal Ilmiah Ekonomi Bisnis, 6(2), 176-185. https://doi.org/10.35972/jieb.v6i2.345.

iRamayanti, R. (2021). Evaluasi Program Praktek Lapangan Industri Jurusan Teknik Elektro Universitas $\begin{array}{llll}\text { Negeri Padang. } & \text { 02(02), }\end{array}$ http://jpte.ppj.unp.ac.id/index.php/JPTE/article/view/90/59.

Suryani, N. L. (2019). Pengaruh Lingkungan Kerja Non-Fisik dan Komunikasi terhadap Kinerja Karyawan pada PT. Bangkit Maju Bersama Di Jakarta. JENIUS (Jurnal IImiah Manajemen Sumber Daya Manusia), 2(3), 419-435. https://doi.org/10.32493/jjsdm.v2i3.3017.

Tjiptono, F. (2012). Service Manajemen: Mewujudkan Layanan Prima. Andi.

Tjiptono, F. (2014). Pemasaran Jasa. Andi.

Wahyono, P., Husamah, H., \& Budi, A. S. (2020). Guru profesional di masa pandemi COVID-19: Review implementasi, tantangan, dan solusi pembelajaran daring. Jurnal Pendidikan Profesi Guru, 1(1), 51-65. https://doi.org/https://doi.org/10.22219/jppg.v1i1.12462.

Yamit, Z. (2010). Manajemen Kualitas Produk dan Jasa. Ekonisia. 